\title{
GESTÃO SOCIAL E REDES DE POLÍTICAS PÚBLICAS: APROXIMAÇÕES TEÓRICO-CONCEITUAIS
}

\author{
MATOS, Karina Ferreira da Silva ${ }^{1}$ \\ MENDES, Wesley de Almeida ${ }^{2}$ \\ MORAIS, Mateus Cerqueira Anícioº \\ MAGALHÃES, Fernanda Gabriela Gandra Pimenta ${ }^{3}$
}

\begin{abstract}
RESUMO: A discussão sobre a importância da participação da sociedade nos processos políticos e, de forma singular, no processo de formulação de políticas públicas tem se tornado cada vez mais relevante. Entretanto, observa-se que as demandas e necessidades da sociedade, muitas vezes não chegam aos representantes de forma clara e concisa e/ou não atingem a visibilidade necessária para que o governo tome algum posicionamento. Diante do exposto, nota-se que a mobilização da sociedade em prol de objetivos em comum e para o bem comum, é de suma importância para que o processo político seja efetivamente democrático e participativo, questões elucidadas pelo conceito de redes de políticas públicas. Desta forma, neste trabalho busca-se identificar as aproximações teóricoconceituais existentes entre a gestão social e as redes de políticas públicas. Conclui-se, que gestão social e redes de políticas públicas se aproximam principalmente no tripé participação, interação e mobilização, que tangenciam os dois conceitos e são de suma importância para que o processo democrático aconteça e para que se alcance o bem comum.
\end{abstract}

Palavras-Chave: Gestão Social. Redes de Políticas Públicas. Participação. Interação. Mobilização

\section{SOCIAL MANAGEMENT AND PUBLIC POLICY NETWORKS: THEORETICAL-CONCEPTUAL APPROACHES}

\begin{abstract}
SUMMARY: The discussion about the society's participation importance in political processes and, specifically, in the public policies formulate process has become increasingly relevant. However, it is observed that the demands and needs of society often do not reach the representatives clearly and concisely and / or do not reach the necessary visibility for the government to take some position. In view of the above, it is important to note that the society mobilization towards common goals and for the common good is of the utmost importance for the political process to be effectively democratic and participatory, issues elucidated by the concept of public policy networks. In this way, this work seeks to identify the theoretical-conceptual approaches that exist between social management and public policy networks. It is concluded that social management and networks of public policies are mainly close to the tripod participation, interaction and mobilization, which tangentiate the two concepts and are of paramount importance for the democratic process to happen and for the common good to be achieved.
\end{abstract}

Keywords: Social Management. Public Policy Networks. Participation. Interaction. Mobilization

\section{INTRODUÇÃO}

A discussão sobre a importância da participação da sociedade nos processos políticos e de maneira singular no processo de formulação de políticas públicas tem se tornado cada vez mais frequente. As oportunidades de engajamento social no Brasil tornaram mais fortes a partir da redemocratização do país em 1988, como apontam os estudos de Jakob (2014) e Tenório (2005).

\footnotetext{
${ }^{1}$ Universidade Federal de Viçosa - Doutoranda em Extensão Rural

${ }^{2}$ Universidade Federal de Viçosa - Doutorando em Administração

${ }^{3}$ Universidade Federal de Viçosa - Mestre em Administração
} 
A Carta Magna, instituída naquele ano, reforçou a participação da sociedade na formulação e consolidação de políticas públicas, salientou a descentralização do processo político e administrativo, propiciando legalmente a aproximação entre agentes estatais e a sociedade civil (JAKOB, 2014; TENÓRIO, 2005). Ressalta-se, contudo, a necessidade latente deixada, de se construir mecanismos práticos, facilitadores de processos participativos para a efetividade das leis herdadas na nova constituição.

$\mathrm{Na}$ literatura brasileira em administração pública, um conceito chave para a efetividade da gestão participativa, como apontado pela constituinte, é o de gestão social. Que pode ser entendida como o gerenciamento da coisa pública baseado em processos dialógicos, abertos à participação dos diversos grupos sociais interligados à administração estatal (BOULLOSA; SCHOMMER, 2008; TENÓRIO, 2005).

Em termos práticos, como destacado por Oliveira et al (2010), a sociedade brasileira tem recriado espaços públicos favoráveis ao debate e à ações públicas coletivas. Tais espaços constituíram uma das bases para a consolidação da gestão social no Brasil, após o período de redemocratização do país. Sobre este processo, Boullosa e Schommer (2008) destacam o amadurecimento desse tipo de gestão pública, que foi impulsionada por diversos elementos, dentre eles a difusão das experiências da agenda 21 no Brasil, a mobilização e articulação de movimentos sociais, a proclamação do terceiro setor, o movimento da responsabilidade social empresarial e do desenvolvimento sustentável.

Diante desta crescente importância da articulação da sociedade e da participação no processo deliberativo, Muller et al (2012) apontam que cada vez mais pesquisas em políticas públicas se empenham em destacar as relações entre instituições governamentais e os atores não estatais, evidenciando, desta forma, o quanto a articulação e participação da sociedade influencia os processos políticos.

Para os autores, a crescente análise de redes de políticas públicas seria uma das respostas à descentralização do Estado, à flexibilização das fronteiras entre público e privado e à articulação da sociedade (MULLER et al, 2012). A literatura especializada aponta que "Redes" são um conjunto de relações estáveis, não hierárquicas e interdependentes, compostas por atores engajados por um objetivo comum (JAKOB, 2014).

Tendo em vista a contemporaneidade e possível aderência conceitual entre os constructos de Gestão Social e Redes de Políticas Públicas no contexto Brasileiro, busca-se nesse trabalho identificar potenciais aproximações teórico-conceituais entre os conceitos de gestão social e as redes de políticas públicas. Acredita-se que esforços científicos nesse sentido oferecem bases para o esclarecimento a respeito das convergências teóricas, bem como para o estabelecimento de limites conceituais entre estes caros conceitos para a literatura contemporânea em administração pública.

\section{GESTÃO SOCIAL}

França Filho (2008) aponta que a existência de um processo de política de auto-organização social, acontece por meio de diferentes modalidades de associações. Para o autor, essas associações devem ser valorizadas e estimuladas, para que possamos alcançar uma democratização por meio da sociedade.

Neste sentido, cabe pensar na gestão social, enquanto um instrumento facilitador de meios de participação e articulação social. Tenório (1998) ressalta que a gestão social preza por um gerenciamento mais participativo, buscando trocar a gestão tecnoburocrática por um processo decisório mais dialógico, onde atuam os diferentes sujeitos sociais.

Segundo Boullosa e Schommer (2008) a gestão social é um modo de gestão originário de contextos sociais, que por vezes acontecem no espaço de organização da sociedade civil e de suas interações com o Estado e o mercado. 
Para Tenório (2005) gestão social pode ser entendida como um processo gerencial dialógico onde a autoridade decisória é compartilhada entre os participantes da ação e onde existe um espaço favorecido de relações sociais em que todos têm o direito à fala, sem sofrer nenhum tipo de coação. Desta forma, segundo Boullosa e Schommer (2008), a gestão social pode ser vista como um construto estratégico capaz de dar sentido e possibilitar constantes experiências que interligam diferentes atores como o Estado, o mercado e a sociedade civil.

Contudo, França Filho (2008) sugere que é importante reconhecer que a gestão social refere-se a algo que acontece num espaço público. Desta forma, representando uma articulação entre o Estado e a sociedade. Entretanto, não se reduz a esfera governamental, pois a gestão social é uma ação política das organizações no sentido de atuarem num espaço público. O autor destaca que a gestão social possibilita que a gestão das demandas e necessidades do social podem se dar via a própria sociedade, por meio de várias formas de auto-organização.

Para Boullosa e Schommer (2008) a expressão gestão social pode designar várias práticas sociais, seja entre organizações governamentais, da sociedade e do âmbito empresarial, associando-se a uma nova configuração das relações entre Estado e sociedade para enfrentar os desafios e problemas atuais.

Para tanto, segundo Cançado et al (2011) a gestão social tem como base a tomada de decisão coletiva, sem coerção. Fundamentando-se na inteligibilidade da linguagem, na dialogicidade e no entendimento esclarecido como processo. Tendo como pressuposto a transparência e a emancipação enquanto fim. Desta forma, segundo Tenório (1998, p.2) "a gestão social deve atender, por meio da esfera pública, ao bem comum da sociedade".

Neste contexto, cabe considerar a importância do Novo Serviço Público enquanto um facilitador da gestão social, entendendo-o como um ponto principal para a um ambiente favorável para a participação, decisão coletiva e controle por parte da sociedade.

Segundo Denhardt (2012) os cidadãos são donos do governo e portanto devem atuar juntos para que se alcance um bem maior. Considerando que o interesse público não se restringe a simples agregação dos interesses individuais. Sendo, portanto mais exigente do que isto, o interesse público, residiria na procura por valores compartilhados e interesses comuns, onde o processo de descoberta se daria por meio de um amplo diálogo e do engajamento de cidadãos. Contudo, o próprio serviço público deve ser mobilizado para servir os outros e a alcançar os objetivos públicos.

O novo serviço público conta com sete princípios chave, sendo eles: 1) Servir cidadãos, não consumidores; 2) Perseguir o interesse público; 3) Dar mais valor à cidadania e ao serviço público do que ao empreendedorismo; 4) Pensar estrategicamente, agir democraticamente; 5) Reconhecer que a accountability não é simples; 6) Servir em vez de dirigir; 7) Dar valor as pessoas, não apenas a produtividade (DENHARDT, 2012).

Estes princípios tangenciam a importância de se perceber o serviço público como sendo uma forma ou extensão da cidadania, onde o governo deve corresponder as necessidades dos cidadãos, promovendo a cidadania e servindo ao interesse público. Desta maneira, os administradores trabalhariam de forma a servir aos cidadãos, de forma a possibilitar o envolvimento e a participação dos mesmos no desenvolvimento da política. Sendo que, tanto os cidadãos como os servidores públicos possuem responsabilidade de identificar problemas e implementar soluções.

O novo serviço público está fundamentado na ideia do interesse público, indicando que os administradores públicos devem estar de fato a serviço dos cidadãos e totalmente envolvidos com eles. Ademais, o Novo Serviço Público se baseia no argumento que a administração pública deve reconhecer a existência de uma cidadania engajada e esclarecida, sendo esta crítica para que aconteça a governança democrática (DENHARDT, 2012). Tais elementos são apresentados como condição sine qua 
non para o desenvolvimento de uma efetiva gestão social.

Desta maneira, entende-se, segundo Dallabrida (2007), que a governança seria uma nova forma de governar, apoiada na interação entre redes de instituições e atores públicos, priorizando interesses coletivos e a prática democrática.

Neste sentido, o autor aponta os aspectos mais evidenciados na literatura sobre governança estão relacionados à legitimidade do espaço público; à distribuição do poder; aos mecanismos de negociação entre os atores sociais; à descentralização da autoridade e das funções relacionadas a prática de governar.

Cançado et al (2013) ressaltam que a governança territorial e a gestão social estão particularmente próximas em decorrência do fato que todo território é um espaço socialmente construído, abrigando diversas relações sociais e possibilitando a realização da democracia deliberativa plena.

Diante do exposto e considerando o objetivo deste trabalho, considera-se relevante apontar os principais aspectos a respeito da governança territorial, principalmente por se entender que os conceitos de gestão social, redes de políticas públicas e governança territorial estão interligados.

Dallabrida (2007) introduz o termo governança territorial, relacionando-o com o desenvolvimento territorial e o processo de gestão social dos territórios. Para tanto, considera governança territorial como sendo o conjunto de ações que demonstram a capacidade de uma sociedade organizada territorialmente, para conduzir os assuntos públicos a partir da relação conjunta dos atores sociais, econômicos e institucionais, buscando um processo de gestão do desenvolvimento territorial.

Desta forma para Dallabrida (2007) a governança territorial aconteceria pela interação de diferentes atores da sociedade, onde interesses grupais são representados através de redes de poder sócioterritorial. Entendendo, que as redes se formam a partir da hipótese de que indivíduos com diferentes desejos e necessidades se agrupam pelos objetivos semelhantes, passando a interagir e a formar redes, neste caso, em territórios.

Segundo Dallabrida (2007, p. 6) o termo rede se refere "ao conjunto de relações de comunicação que grupos sociais situados historicamente num determinado território, estabelecem para atingir objetivos comuns com vistas ao desenvolvimento territorial".

Dallabrida (2007) ressalta que a participação ativa dos atores locais no que tange o exercício da governança territorial, concretiza-se nos processos de concertação social, constituindo-se numa das condições fundamentais para que se tenha efetivamente uma gestão social dos territórios.

A existência de uma a abertura que possibilite a participação da sociedade no processo de formulação de políticas públicas, permite que esta se articule e que, em decorrência disso ocorra o surgimento de redes de políticas públicas.

\section{REDES DE POLÍTICAS PÚBLICAS}

O conceito de rede de políticas públicas é polissêmico e é apresentado por diversos autores da área. Calmon e Costa (2013) afirmam que as redes de políticas públicas possui um caráter inovador, combinando conhecimentos de diversas áreas e contrapondo-se a percepção de que o Estado estaria acima do restante da sociedade.

Segundo Jakob (2014, p.105) "uma rede constitui-se em um conjunto de relações relativamente estáveis, não hierárquicas e interdependentes que ligam uma variedade de atores com objetivos comuns, no qual a cooperação é o melhor modo de alcançá-los".

Santos (2005, p.4), por sua vez, entende "redes de políticas públicas como sendo a caracterização geral do processo de formulação de políticas na qual membros de uma ou mais comunidades de políticas estabelecem uma relação de interdependência”. O autor ressalta que este fenômeno pode ser entendido 
como a caracterização geral do processo de formulação de políticas na qual os membros de comunidades de políticas constituem uma relação de interdependência.

Pode-se entender que as redes de políticas públicas possuem a capacidade de mobilizar atores para a resolução de problemas coletivos, englobando atores sociais advindos de múltiplos segmentos sociais e políticos em contextos de produção de políticas (SCHNEIDER, 2005; JAKOB, 2014). Segundo Luchini et al (2003) as redes viabilizam uma maior eficácia das políticas públicas, bem como uma adaptação das organizações públicas às variações do contexto onde elas atuam.

Para Schneider (2005) o conceito de redes de políticas públicas acarreta uma visão da realidade na qual as políticas públicas não são formuladas e implementadas apenas pelo Estado, mas que também atores privados ou sociais interagem e participam nesse processo de produção e oferta de bens públicos.

Nesse sentido, Luchini et al (2003) destaca a importância de entender que as redes de políticas públicas têm em sua proposta como pano de fundo, a descentralização, a participação e a transparência. Indicando que, para se alcançar resultados efetivos são necessárias mudanças no âmbito cultural do Estado e da sociedade, que devem se voltar para questões que priorizem o bem comum.

Com relação os elementos que caracterizam redes de políticas públicas, Calmon e Costa (2013) ressaltam que tal conceito tende a abranger quatro elementos fundamentais: a heterogeneidade e interdependência entre atores, a existência de um subsistema e a presença de uma estrutura de governança.

Os autores trazem pontos importantes para as análises de redes de políticas públicas. Os mesmos ressaltam que os recursos financeiros, políticos e organizacionais necessários, estão distribuídos em uma vasta gama de organizações e atores, estais ou não. Desta forma ao se analisar as redes de políticas públicas pode-se identificar elementos adicionais que interferem de forma importante nas redes de políticas públicas. Como por exemplo, os problemas de ação coletiva, questão que demonstra a multiplicidade de atores e objetivos, que necessariamente precisam de formas para resolver problemas que tangenciam a coordenação, cooperação e comunicação. Sendo que muitas vezes estão inseridos em um ambiente que gera ambiguidades e incertezas.

Outra questão apontada por Calmon e Costa (2013), é a interdependência, fator que deve ser considerado fundamental nas redes de políticas públicas. Neste contexto, Santos (2002) ressalta que as políticas públicas devem ser resultado da interação entre agências estatais e organizações não estatais.

Desta forma, cabe trazer para esta reflexão duas vertentes que tratam a questão da participação por meio da rede de política pública de formas distintas. Sendo elas o neopluralismo e o neocorporativismo.

Este apontamento se faz importante pois, segundo Santos (2002), para os neopluralistas, nem todos os grupos tem o mesmo acesso ao processo de formulação de políticas públicas, considerando que mesmo em uma sociedade democrática existem uma concorrência entre diferentes grupos, tanto por recursos como também por poder.

Contudo, as redes de políticas públicas neopluralistas podem ser entendidas, como uma estrutura em que mesmo quando os diversos atores não possuem igualdade de acesso ao processo de formulação não haveria um ator que assumiria um papel principal de legitimador da participação de todos os atores interessados. Entretanto esta abordagem recebe críticas que tangenciam principalmente sua falta de compreensão do processo político vigente.

Em contra partida, segundo Santos (2002) o neocorporativismo é um sistema articulado de representação de interesses, onde o papel do Estado pode definir os canais de participação dos demais atores. Portanto, nesta perspectiva o Estado teria uma grande poder regulador no que diz respeito a participação.

Neste contexto, Santos (2002), aponta as principais diferenças existentes entre as duas vertentes aqui destacadas. Entendendo que as redes de políticas públicas de tipo neopluralista, precisam de pelo 
menos quatro condições para a sua existência, sendo elas: uma abertura ao processo político e a arena de formulação de políticas; um processo concorrido e conflitivo de definição de políticas; a ausência de grupos de interesse superpoderosos; e a objetividade do Estado para tratar das questões de políticas públicas.

Em relação as redes de políticas públicas de tipo neocorporativista, o autor ressalta, que a principal diferença se encontra na escolha dos participantes, sendo que estes são determinados pelo Estado ou por uma agência estatal. $\mathrm{O}$ autor entende que se trata de tipos-ideais, e que desta forma, a realidade pode apresentar elementos de ambas abordagens.

De forma a sintetizar as diferenças existentes nestas duas abordagens Santos (2002), aponta algumas situações. O autor esclarece que quanto ao número de grupos nas redes de políticas públicas neopluralista eles tendem a ser expressivos e na neocorporativista os grupos são limitados. Em relação aos interesses, nas redes neopluralista eles se sobrepõem e nas redes corporativista os interesses são estabelecidos. No que tange a estrutura das redes, na neopluralista não existe hierarquia, já na corporativista observa-se a existência de hierarquia.

Segundo Marques (2006) pode-se entender que as redes estruturam várias dimensões sociais, considerando que toda situação social é formada por um "conjunto de atores dotados de instrumentos de poder que disputam os resultados do processo político em termos da distribuição de benefícios escassos e poder político" (MARQUES, 2006, p.17).

Contudo, os estudos de redes de políticas públicas permitem que se discuta os efeitos da interdependência da ação social e do Estado na produção de políticas e também que incorpore relações informais as análises (MARQUES, 2006).

Neste sentido, segundo Monteiro e Fleury (2012), as redes de políticas públicas, criaram novas ordenações entre os atores privados e públicos, buscando influenciar em diferentes momentos dos ciclos da política pública, como por exemplo tornar um problema visível e introduzir um problema na agenda governamental.

Conclui-se, como demonstra Schneider $(2005$, p.1) que "rede e governança são conceitos que pontuam que a solução de problemas políticos modernos e relevantes por meio de políticas públicas, somente é possível com base em novas estruturas políticas", como por exemplo a gestão social, que possibilita uma abertura a participação da sociedade no processo político.

\section{CONVERGÊNCIAS TEÓRICOS CONCEITUAIS ENTRE GESTÃO SOCIAL E REDES DE POLÍTICAS PÚBLICAS}

Após a análise da literatura referente a gestão social e a redes de políticas públicas, como forma de demonstrar as aproximações existentes, delineia-se três proposições que sugerem os principais pontos de convergência entre tais conceitos.

Convergência 1: A descentralização como peça fundamental para a participação

Neste sentido, é apontado a importância da descentralização, que aconteceu em decorrência do processo de democratização. Permitindo assim, uma maior participação da sociedade no processo político, como apontam Tenório (2005); Muller et al (2012); Dallabrida (2007); Luchini et al (2003) e Jakob (2014). Tais autores colaboram para o entendimento de que a descentralização permitiu não só uma 
abertura à participação mais também a consolidação de atores não estatais no processo político. Confirmando que na nova lógica decisória da gestão social caberia a interação das redes de políticas públicas.

Convergência 2: As políticas públicas devem ser resultado da interação entre o estado e os atores nãoestatais

Tal proposição baseia nos argumentos expostos por Carvalho (2001); Muller et al (2012); Boullosa e Schommer (2008); Tenório (2005); Filho (2008); Calmon e Costa (2013) e Schneider (2005), que expõem a importância desta articulação entre atores não-estatais e o Estado para a formulação de políticas públicas. As considerações sobre a aproximação a respeito da gestão social e redes de políticas públicas podem ser observadas em diferentes estudos, como de Boullosa e Shommer (2008) e de Shneider (2005).

Segundo Boullosa e Schommer (2008), a gestão social podia ser vista como um construto estratégico capaz de dar sentido e possibilitar constantes experiências que interligam diferentes atores como o Estado, o mercado e a sociedade civil.

Conforme Schneider (2005), o conceito de redes de políticas públicas acarreta uma visão da realidade na qual as políticas públicas não são formuladas e implementadas apenas pelo Estado, mas que também atores privados ou sociais interagem e participam nesse processo de produção e oferta de bens públicos.

Convergência 3: Mobilização e articulação da sociedade em prol de objetivos para o bem comum

Observa-se que os autores Filho (2008); Boullosa e Schommer (2008) e Carvalho (2001), apontam a importância da mobilização e articulação dos atores-não estatais. Sendo possível perceber que esta importância se estende à gestão social bem como às redes de políticas públicas. Identificando-se que as políticas públicas que atendem as demandas e necessidades da sociedade passam por este momento de mobilização e articulação a respeito de problemas ou interesses comuns, para que sejam inseridos na agenda política.

\section{CONSIDERAÇÕES FINAIS}

A democratização do país, foi um marco que possibilitou a participação da sociedade no processo político, permitindo desta forma que os atores não-estatais ganhassem voz e direito de expor suas necessidades e cobrar por ações que visassem soluções plausíveis para os problemas públicos.

Nota-se, na literatura em questão, o apelo de que a identificação de problemas e/ou demandas deve se dar não apenas por iniciativa do Estado, mas também por atores não-estatais, sendo que, dessa interação, surjam políticas públicas que efetivas, voltadas a suprir as necessidades expostas pela sociedade. Observa-se, nesse processo a importância da mobilização e articulação da sociedade, principalmente em forma de redes, para que através da participação se alcance o bem comum.

A primeira convergência apresentada, se refere à importância da descentralização para a participação efetiva da sociedade, indicando-a como um fator importante que tangencia os conceitos de gestão social e redes de políticas públicas. A segunda convergência identificada, foi a interação entre o Estado e os atores não estatais, que possui grande relevância para os dois temas abordados. A terceira, 
por sua vez, diz respeito à capacidade de mobilização e articulação da sociedade em prol de objetivos para o bem comum, demonstrando o quanto as ações da sociedade podem e devem interferir no processo político.

Assim, tem-se que gestão social e redes de políticas públicas se aproximam principalmente por meio do tripé: participação, interação e mobilização, que tangenciam os dois conceitos e são de suma importância para que o processo democrático aconteça e para que se alcance o bem comum.

Sobre essa análise, pode-se notar que em um contexto democrático, as redes de políticas públicas favorecem um processo mais amplo e em conjunto, abrangendo diversos segmentos sociais, onde a construção de políticas públicas tende a se iniciar pelas demandas originarias dos atores envolvidos. Destaca-se a importância do governo em estar aberto a receber e atender as demandas sociais, bem como a necessidade do engajamento da sociedade organizada no contexto político do país.

Assim, entende-se que este estudo avança ao propor aproximações entre rede de políticas públicas e gestão social e por evidenciar aspectos que podem ser válidos para análises futuras em situações concretas e em contextos específicos. Recomenda-se, assim, a realização de uma análise empírica de forma a identificar, em um caso de estudo, como as bases desse tripé se relacionam na concepção das redes de políticas públicas e de gestão social

\section{REFERÊNCIAS}

BOULLOSA, Rosana de Freitas; SCHOMMER, Paula Chies. Limites da natureza da inovação ou Qual o futuro da Gestão Social? Revista Habitus, v. 10, n.1, p.1-16, 2012.

CALMON, Paulo; COSTA, Arthur Trindade Maranhão. Redes e Governança das políticas públicas. Revista de Pesquisa em Políticas Públicas, v.3, n. 1, p. 1-29, 2013.

CANÇADO, Airton Cardoso; TENÓRIO, Fernando Guilherme; PEREIRA, José Roberto. Gestão social: reflexões teóricas e conceituais. Cadernos EBAPE.BR, v.9, n.3, p.681-703, 2011.

CANÇADO, Airton Cardoso; TAVARES, Bruno; DALLABRIDA, Valdir Roque. Gestão Social e Governança Territorial: interseções e especificidades teórico-práticas. Revista Brasileira de Gestão e Desenvolvimento Regional, v. 9, n. 3, p. 313-353, 2013.

CARVALHO, Maria do Carmo Brant de. Introdução à temática da gestão social. In: Célia M. de Ávila. Gestão de projetos sociais. São Paulo: Associação de Apoio ao Programa Capacitação Solidária, 2001. p.13-18

DALLABRIDA, Valdir Roque. A Gestão Social dos Territórios nos Processos de Desenvolvimento Territorial: Uma Aproximação Conceitual. Sociedade, Contabilidade e Gestão, v. 2, n. 2, p.44-60, 2007.

FRANÇA FILHO, Genauto Carvalho de França. Definindo Gestão Social. In: Práticas em Debate, Teorias em Construção. Juazeiro do Norte: Laboratório Interdisciplinar de Estudos em Gestão Social, 2008. p.26-37

JAKOB, André Codo. Governança, redes de políticas públicas e participação social: uma interseção de literaturas. Revista Brasiliense de Pós-Graduação em Ciências Sociais, v.13, n. 2, p. 100-120, 2014.

LUCHINI, Adriana de Mello; SOUZA, Marcio Domingues; PINTO, Aluizio Loureiro. Aportes e limites da perspectiva de redes de políticas públicas: o caso da gestão da água. Caderno de Pesquisas em

Administração, v. 10, n. 2, p.87-94, 2003. 
MARQUES, Eduardo Cesar. Redes sociais e poder no estado brasileiro: Aprendizados a partir das políticas urbanas. Revista Brasileira de Ciências Sociais, v. 21, n. 60, p. 15-41, 2006.

MONTEIRO, Lilian Alfaia; FLEURY, Sonia. Elos que libertam: Redes de Políticas Públicas para erradicação do trabalho escravo contemporâneo no Brasil. Organizações e Sociedade, v.21, n.69, p. 1-16, 2014.

OLIVEIRA, Vânia Aparecida Rezende de; CANÇADO, Airton Cardoso; PEREIRA, José Roberto. Gestão social e esfera pública: aproximações teórico conceituais. Cadernos EBAPE. BR, v. 8, n. 4, p. 613-626, 2010.

SANTOS, Hermílio. Grupos de interesse e redes de políticas públicas: Uma análise da formulação de política industrial. Civitas - Revista de Ciências Sociais, v.2, n.1, p.193-210, 2002.

SANTOS, Hermílio. Perspectivas contemporâneas para a constituição de redes de políticas públicas.

Civitas - Revista de Ciências Sociais, v. 5. n. 1, p.59-68, 2005.

SCHNEIDER, Volker. Redes de políticas públicas e a condução de sociedades

Complexas. Civitas - Revista de Ciências Sociais, v.5, n.1, p. 29-58, 2005.

TENÓRIO, Fernando Guilherme. Gestão social: uma perspectiva conceitual. Revista de Administração Pública, v.32, n.5, p.7-23, 1998.

TENÓRIO, Fernando Guilherme. (Re)Visitando o Conceito de Gestão Social. Revista Desenvolvimento em Questão, v. 3, n. 5, p. 101-124, 2005. 